\title{
Loss of the Renal Vasoconstrictor Activity of Angiotensin II during Renal Ischemia*
}

\author{
John C. McGiff † And Harold D. Itskovitz \\ (From the Departments of Pharmacology and Medicine, Schools of Medicine, University of \\ Pennsylvania, and the Edward B. Robinette Foundation, Medical Clinic, \\ Hospital of the University of Pennsylvania, Philadelphia, Pa.)
}

The renin-angiotensin system may be involved in the development of experimental renal hypertension (1) and some forms of hypertension in humans (2). According to the most widely accepted hypothesis (3), angiotensinogen (renin substrate) is converted to angiotensin I, a decapeptide, by renin during renal ischemia (4) or reduced mean arterial blood pressure (5). The octapeptide, angiotensin II, is formed from angiotensin I by the converting enzyme in plasma. Angiotensin II, a potent pressor agent, has been suggested to increase renal blood flow (RBF) during renal ischemia secondarily to an increased renal perfusion pressure $(6,7)$. This hypothesis fails to account for the marked renal vasoconstrictor property of angiotensin II (8). The increase in renal vascular resistance (RVR) elicited by angiotensin has been shown to be the largest of ary vascular bed $(9,10)$. Furthermore, renal ischemia has been challenged as a stimulus activating the renin-angiotensin system $(11,12)$.

The present study was undertaken to define the action of angiotensin II during renal ischemia. Abolition of the renal vasoconstrictor activity of angiotensin II was found during renal ischemia. Thus, the pressor effect of angiotensin would promote an increased RBF to an ischemic kidney. The enhanced RBF then may obscure the initial ischemic stimulus. In addition, this study describes the development of altered reactivity of the renal vasculature to the vasoconstrictor proper-

\footnotetext{
* Submitted for publication June 2, 1964; accepted August 17, 1964.

Abstracts of this article appeared in J. clin. Invest. 1963, 42, 954, and Circulation 1963, 28, 767.

Supported by grants from the U. S. Public Health Service, grant He-05139 and general research support grant 1S01-FR05115-01.

$\dagger$ Established investigator, American Heart Association (July 1, 1964).
}

ties of angiotensin II that may occur in the absence of renal ischemia.

\section{Methods}

Twenty-six mongrel dogs weighing 19 to $32 \mathrm{~kg}$ were anesthetized with morphine sulfate $(2 \mathrm{mg}$ per $\mathrm{kg}$, subcutaneously) and chloralose (70 $\mathrm{mg}$ per $\mathrm{kg}$, intravenously). The trachea was cannulated, and the lungs were ventilated by a Starling ideal pump. Heparin ${ }^{1}$ (200 to 400 international $\mathrm{U}$ per $\mathrm{kg}$ ) was administered intravenously as the anticoagulant.

A Sanborn polyviso recorded the following: 1) Mean arterial pressure was recorded by a Statham transducer from a catheter inserted into the right femoral artery. In three experiments aortic blood pressures were recorded proximal and distal to an aortic constriction placed just above the renal arteries to permit determination of renal vascular resistances in the ischemic kidney. 2) The blood flow of one kidney was measured in 22 experiments. In four experiments both RBF's were measured simultaneously. The venous outflows of the kidneys were measured. The renal vein was cannulated; renal arterial flow was interrupted for no more than 2 minutes during renal vein cannulation. Venous cannulation was selected, rather than arterial, for it permits preservation of renal innervation. The effluent was passed through a rotameter $(200 \mathrm{ml})$ of Shipley-Wilson, which was placed below the renal vein. After passage through the rotameter, the blood emptied into a reservoir. The blood was then returned to the femoral vein of the animal by a Sigmamotor pump that was automatically activated by a predetermined level of blood in the reservoir. The volume of blood in the reservoir that was maintained throughout the experiment was $40 \mathrm{ml}$. The entire recording system contained no more than 120 $\mathrm{ml}$ of blood, representing about $6 \%$ of the dog's blood volume. An equal volume of plasma expander $(6 \%$ gelatin solution) was administered in the beginning of the experiment.

Angiotensin II ${ }^{2}$ ( 0.05 to $2.5 \mu \mathrm{g}$ per $\mathrm{kg}$ ), atropine sulfate $(0.2 \mathrm{mg}$ to $2 \mathrm{mg}$ per $\mathrm{kg}$ ), tetraethylammonium chloride (TEAC) (10 mg per $\mathrm{kg}$ ), and epinephrine bitartrate and levarterenol bitartrate $(0.4$ to $2.0 \mu \mathrm{g}$ per $\mathrm{kg})$ were

${ }_{1}$ Panheprin, Abbott Laboratories, North Chicago, Ill. 2 Hypertensin, Ciba Pharmaceutical Co., Summit, N. J. 
TABLE I

Alterations of blood pressure and renal blood flow induced by angiotensin and levarterenol in the ischemic and nonischemic kidneys

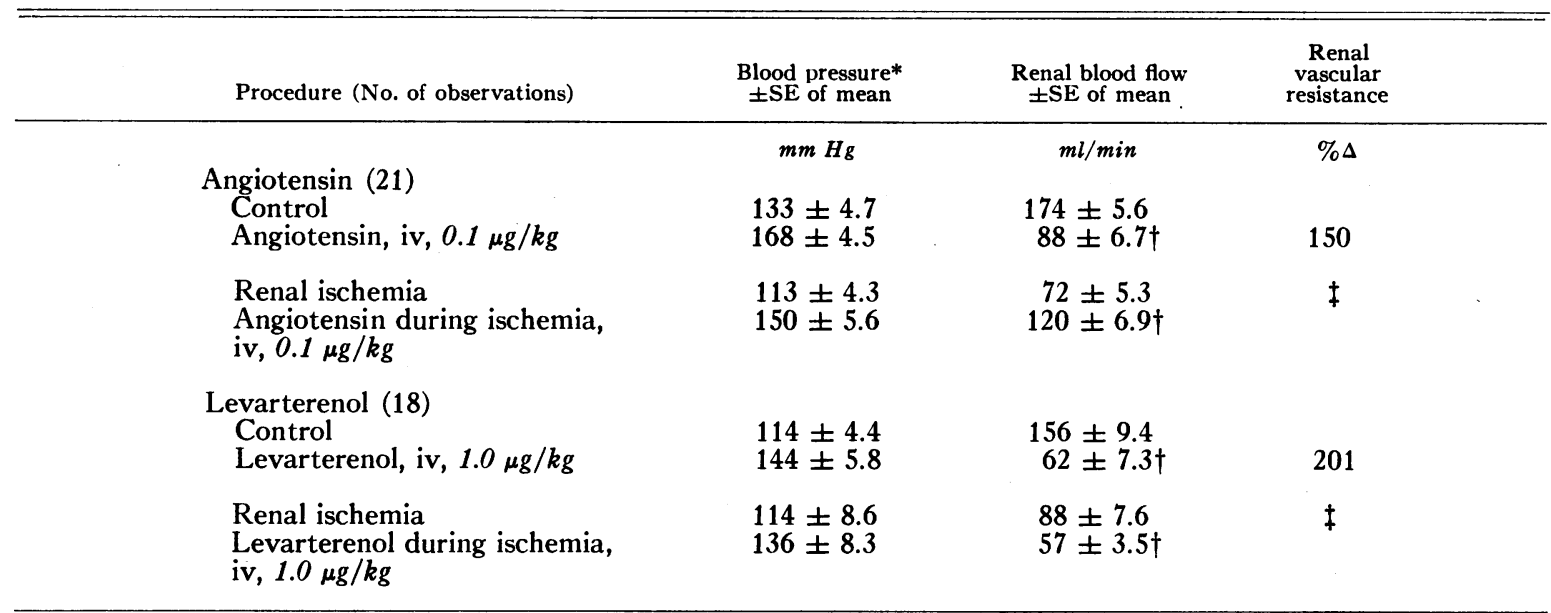

* The blood pressure was measured above the arterial constriction.

$\dagger$ The mean values of the renal blood flows resulting from administration of angiotensin and levarterenol were compared with the mean values of the control renal blood flows. Differences were statistically evaluated; $p<0.001$ for each of the four renal blood flows that were compared.

$\ddagger$ Renal vascular resistances are not available, for perfusion pressure distal to the constriction was measured only during ischemia induced by aortic constriction (see text).

administered intravenously. Intravenous injections of the drugs were made rapidly through a cannulated femoral vein. A catheter was introduced through the carotid artery in five experiments and placed just above the origin of the renal arteries for intra-aortic administration of angiotensin II ( 0.01 to $0.5 \mu \mathrm{g}$ per $\mathrm{kg})$.

Constriction of the renal artery and aorta was accomplished by tightening a ligature passed around the vessel after gentle dissection of its bed. The ligature was tightened without displacing the vessel from its bed; care was taken to avoid traction upon the vessel.

In four experiments acute denervation of the kidney was accomplished by careful dissection of the structures as they traversed the renal hilum. Renal arterial transection was then carried out. The kidney was then perfused with blood from the carotid artery through a cannula inserted into the distal end of the sectioned renal artery. This procedure required 3 minutes of

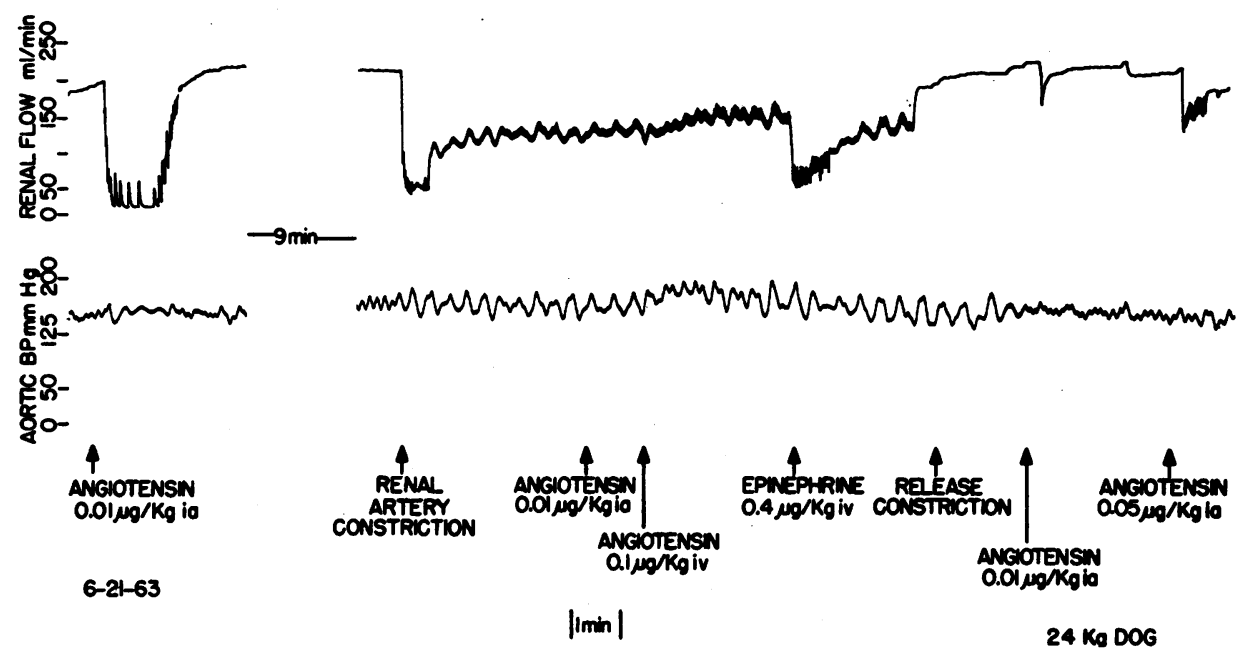

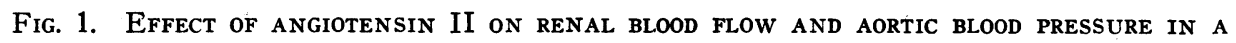
DOG UNDER MORPHINE-CHLORALOSE. The marked sensitivity to angiotensin II administered into the aorta (ia) before renal arterial constriction is contrasted with the effect of angiotensin II during renal ischemia. Epinephrine administered during renal ischemia caused a further reduction in renal blood flow. 
interruption of $\mathrm{RBF}$. Recovery of $\mathrm{RBF}$ was immediate after renal arterial cannulation. The RBF was within $15 \%$ of presection levels in each case.

Vascular resistances were calculated from the maximal change in flow and the simultaneous blood pressure elicited by the stimulus. Statistical analyses were made on paired analyses of control and experimental values of the maximal change in RBF and the associated blood pressure after application of the stimulus. The coeffcient of correlation was calculated for the control blood flow of the ischemic kidneys and the percentage increase in $\mathrm{RBF}$ elicited by angiotensin (13).

\section{Results}

\section{A. Effect of angiotensin II on the nonischemic renal vasculature}

After administration of angiotensin II intravenously, the RVR was increased by $150 \%$ of control values (Table I). Within the range of the dosage employed ( 0.05 to $2.5 \mu \mathrm{g}$ per $\mathrm{kg}$, intravenously, or 0.01 to $0.5 \mu \mathrm{g}$ per $\mathrm{kg}$, intra-arterially), there was no constant relationship between the magnitude of the changes in the RVR and the dose of angiotensin II. With the appearance of reduced vascular reactivity, the threshold dose of angiotensin II necessary to constrict the renal vessels was elevated.

\section{B. Reduced vascular response of the nonischemic renal vasculature to angiotensin II}

Altered renal vascular reactivity, to angiotensin II, which generally followed several periods of renal ischemia, was noted frequently. In Figure 1 , after release of the renal arterial constriction, the $\mathrm{RBF}$ response to intra-aortic administration of angiotensin II was markedly diminished.

The appearance of reduced vascular reactivity to angiotensin II was accelerated by periods of renal ischemia. Figure 2 traces the evolution of the reduced vascular response of the renal bed to angiotensin II. The marked sensitivity of the renal bed to angiotensin II was progressively diminished over an 85-minute period of observation, until finally the vasoconstrictor action of angiotensin II was abolished. The loss of the renal vascular activity of angiotensin II was not accompanied by a loss of response of the renal vasculature to levarterenol or epinephrine (Figure 2).

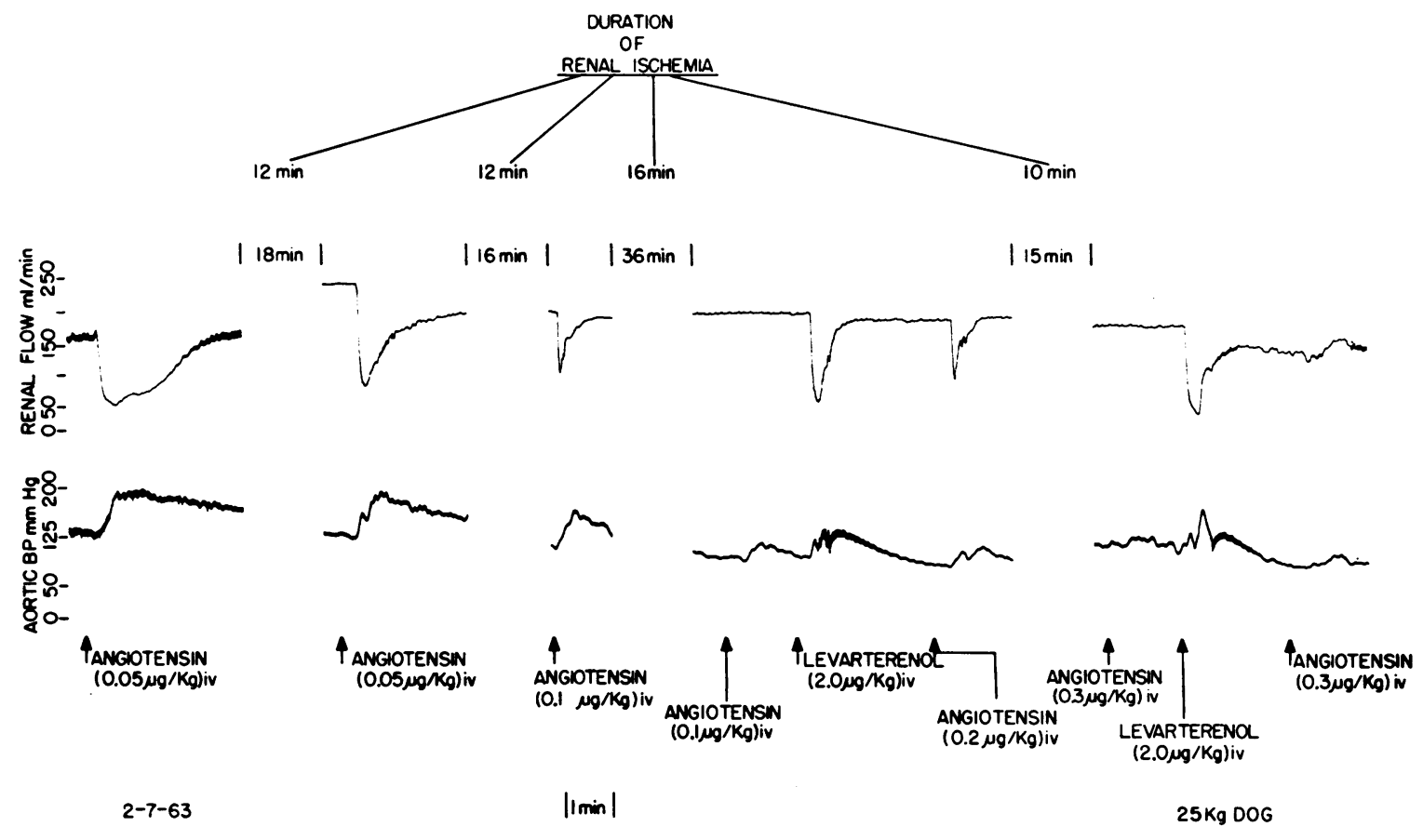

Fig. 2. Development of Refractoriness of the renal vascular bed to ANGiotensin II in a dog UNder MORPHINE-CHLORALOSE. With the loss of response to angiotensin II, levarterenol continued to elicit vasoconstriction. The period between drug administration is indicated, and the part of that period during which renal ischemia was maintained is indicated above. 


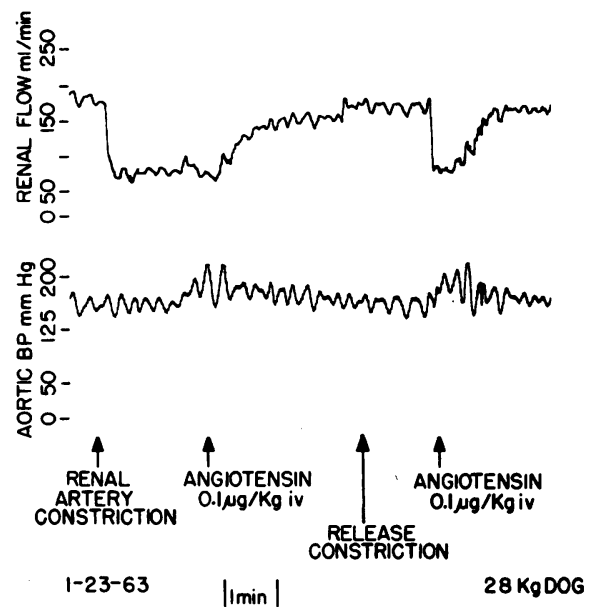

Fig. 3. Paradoxical efFect of angiotensin II dURING RENAL ISCHEMIA IN A DOG UNDER MORPHINE-CHLORALOSE. The renal blood flow was restored almost to control levels after administration of angiotensin II during renal ischemia. Immediately after release of the renal arterial constriction, angiotensin II caused a reduction of renal blood flow.

TEAC failed to restore the reactivity of the renal blood vessels to angiotensin II.

\section{Effect of angiotensin II on the ischemic renal vasculature}

During acute reductions in RBF caused by either renal arterial constriction or constriction of the abdominal aorta, administration of angiotensin II intravenously elicited an increased RBF simultaneously with a pressor response. During comparable degrees of renal ischemia, levarterenol demonstrated only a further reduction in RBF. Table I depicts the changes in RBF and blood pressure produced by equipressor doses of angiotensin II and levarterenol in the nonischemic and ischemic kidneys. There is no significant difference $(p>0.05)$ in the degree of elevation of blood pressure elicited by angiotensin II and levarterenol during renal ischemia (Table I). Figure 3 illustrates the almost complete restoration of RBF of an ischemic kidney to control levels after an intravenous injection of angiotensin II. Ninety seconds after release of the constriction, the same dose of angiotensin II that produced an increase in $\mathrm{RBF}$ now elicited a sharp reduction in RBF (Figure 3).

The loss of angiotensin renal vasoconstriction during renal ischemia was observed 42 times in 24 experiments. During three ischemic periods in three experiments, angiotensin II elicited a further reduction of RBF. In two of these periods, the ischemic RBF's were considerably above (115 and $140 \mathrm{ml}$ per minute) the mean values of ischemic RBF's (72 $\mathrm{ml}$ per minute). In these three exceptions, after increasing the degree of ischemia, administration of angiotensin II intravenously increased the RBF. In those experiments in which an increased RBF was produced by angiotensin II during induced ischemia, the $\mathrm{RBF}$ was reduced by $35 \%$ to $77 \%$ below control RBF's. It appeared that a reduction below $30 \%$ of control RBF was necessary to produce loss of the renal vascular action of angiotensin II.

\section{Mechanism of the loss of angiotensin II renal vasoconstrictor activity}

1) Effect of catecholamines during renal ischemia. Epinephrine or levarterenol (0.4 $\mu \mathrm{g}$ to 1.0

TABLE II

Response to angiotensin II of the renal blood flows, simultaneously measured, of an ischemic and normal kidney*

\begin{tabular}{|c|c|c|c|c|c|c|}
\hline \multirow[b]{2}{*}{$\begin{array}{l}\text { Angiotensin II } \\
\text { iv }\end{array}$} & \multicolumn{2}{|c|}{ Blood pressure } & \multicolumn{2}{|c|}{ Ischemic kidney } & \multicolumn{2}{|c|}{ Normal kidney } \\
\hline & Control & $\% \Delta$ & $\begin{array}{l}\text { Control } \\
\text { RBF }\end{array}$ & $\begin{array}{c}\% \Delta \\
\text { RBF }\end{array}$ & $\begin{array}{c}\text { Control } \\
\text { RBF }\end{array}$ & $\begin{array}{r}\% \Delta \\
\mathrm{RBF}\end{array}$ \\
\hline$\mu g / k g$ & \multicolumn{2}{|c|}{$m m \mathrm{Hg}$} & \multicolumn{2}{|c|}{$\mathrm{ml} / \mathrm{min}$} & \multicolumn{2}{|c|}{$\mathrm{ml} / \mathrm{min}$} \\
\hline 0.1 & 140 & +21 & 85 & +35 & 155 & -55 \\
\hline 0.1 & 100 & +40 & 40 & +100 & 90 & -47 \\
\hline 0.2 & 85 & $\begin{array}{r}10 \\
+47\end{array}$ & 75 & $\begin{array}{l}1 \\
+\quad 20\end{array}$ & 125 & -48 \\
\hline 0.2 & 75 & +20 & 50 & $\begin{array}{l}T \\
+80\end{array}$ & 115 & -65 \\
\hline 0.3 & 80 & +25 & 80 & +25 & 115 & -13 \\
\hline 0.4 & 80 & +38 & 75 & +33 & 150 & -68 \\
\hline 0.5 & 95 & +32 & 75 & +60 & 136 & -15 \\
\hline
\end{tabular}

* Abbreviations: $\% \Delta$ blood pressure $=$ the per cent change from control of the mean aortic pressure induced by angiotensin II ; RBF = renal blood flow in milliliters per minute; $\% \Delta \mathrm{RBF}=$ the per cent change of renal blood flow relative to control values (left column). 

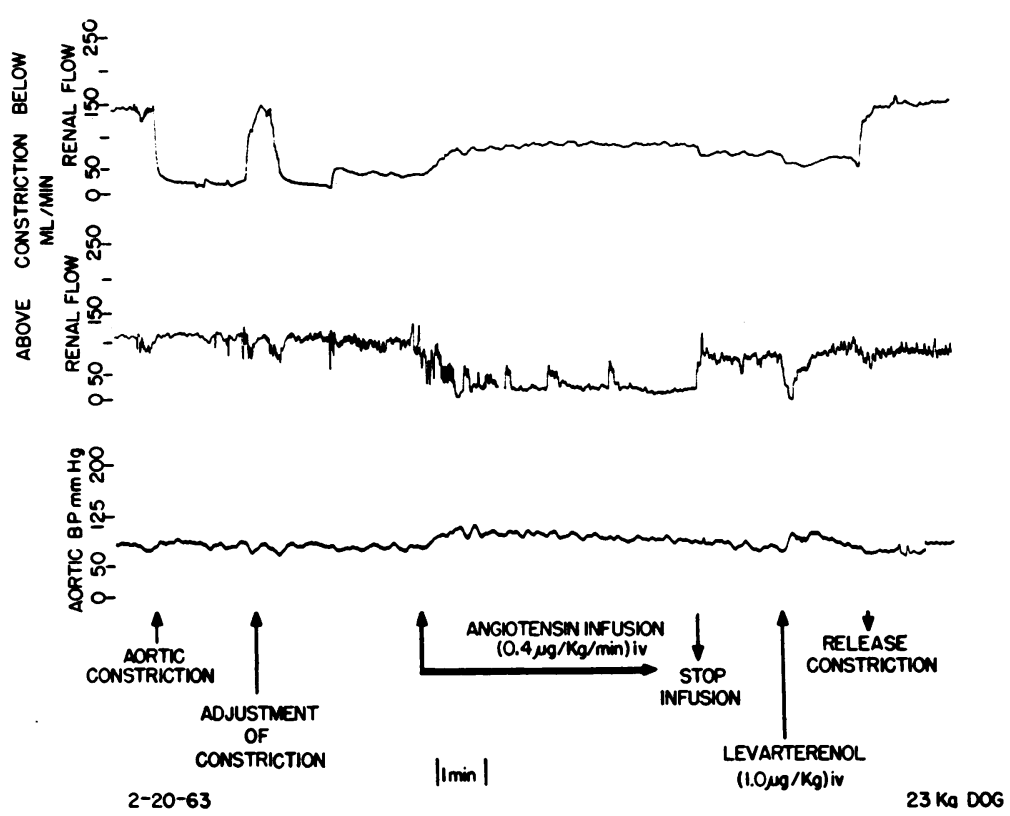

Fig. 4. RESPONSE OF AN ISCHEMIC AND A NONISCHEMIC KIDNEY To ANGIOTENSIN II IN A DOG UNDER MORPHINE-CHLORALOSE. After induction of renal ischemia, an angiotensin II infusion caused a prompt reduction in the blood flow to the nonischemic kidney (lower tracing) and an increase in the blood flow to the ischemic kidney (upper tracing). Administration of levarterenol during renal ischemia produced a reduction in both blood flows.

$\mu \mathrm{g}$ per $\mathrm{kg}$ ) produced a further reduction of $\mathrm{RBF}$ during renal ischemia (Figure 1, Table I).

2) Role of a reduction in renal blood flow. In order to evaluate the effect of a reduction in RBF on angiotensin activity, hemorrhagic hypotension and levarterenol infusions were employed in two experiments each. Hemorrhagic hypotension (15 to $20 \mathrm{ml}$ per $\mathrm{kg}$ ) and levarterenol infusion $(2 \mu \mathrm{g}$ per $\mathrm{kg}$ per minute) caused reductions of $\mathrm{RBF}$ similar to those induced by renal arterial constriction (30 to $70 \%$ ). Administration of angiotensin II during these periods of reduced RBF caused a further reduction of $\mathrm{RBF}$.

3) Two renal blood flows measured simultaneously (Table II). In four experiments the blood flows of each kidney were measured simultaneously. Constriction of the abdominal aorta between the origin of the renal arteries resulted in

TABLE III

Renal vascular resistance changes induced by angiotensin II during renal ischemia*

\begin{tabular}{|c|c|c|c|c|c|c|c|c|c|c|c|c|}
\hline & \multicolumn{2}{|c|}{$\mathrm{BP}$} & RBF & RVR & \multicolumn{2}{|c|}{ BP } & RBF & RVR & \multicolumn{2}{|c|}{ BP } & $\mathrm{RBF}$ & RVR \\
\hline & \multicolumn{2}{|c|}{$\mathrm{mm} \mathrm{Hg}$} & \multicolumn{2}{|l|}{$\mathrm{ml} / \mathrm{min}$} & \multicolumn{2}{|c|}{$\mathrm{mm} \mathrm{Hg}$} & \multicolumn{2}{|l|}{$m l / \min$} & \multicolumn{2}{|c|}{$m m \mathrm{Hg}$} & $\mathrm{ml} / \mathrm{min}$ & \\
\hline Control & $\begin{array}{l}\text { Below } \\
\text { constr. }\end{array}$ & 135 & 190 & 0.71 & $\begin{array}{l}\text { Below } \\
\text { constr. }\end{array}$ & 105 & 160 & 0.66 & $\begin{array}{l}\text { Below } \\
\text { constr. }\end{array}$ & 85 & 185 & 0.46 \\
\hline Aortic constriction & 30 & 155 & 65 & 0.46 & 40 & 100 & 40 & 1.00 & 35 & 80 & 75 & 0.47 \\
\hline $\begin{array}{l}\text { Angiotensin, } \\
\text { iv, } 0.15 \mu \mathrm{g} / \mathrm{kg}\end{array}$ & 40 & 165 & 90 & 0.44 & 70 & 140 & 70 & 1.00 & 75 & 95 & 135 & 0.56 \\
\hline Recovery & & 85 & 190 & 0.45 & & 95 & 130 & 0.73 & & 70 & 125 & 0.56 \\
\hline
\end{tabular}

* Abbreviations: $\mathrm{BP}=$ mean aortic blood pressure in millimeters $\mathrm{Hg}$ recorded below and above an aortic constriction; the two values in the left column under below constr. are the blood pressures below the aortic constriction; RBF $=$ renal blood flow in milliliters per minute; $\mathrm{RVR}=$ renal vascular resistance; during aortic constriction the aortic blood pressure below the constriction represents renal perfusion pressure, which was used for calculating RVR during the period of renal ischemia. 
ischemia of the left (lower) kidney and no significant alteration of the blood flow to the right kidney. Angiotensin II by intravenous injection or infusion consistently elicited opposite changes in the RBF's during aortic constriction (Figure 4 and Table II). An increase of $50 \%$ of the blood flow of the ischemic kidney occurred simultaneously with a $44 \%$ decrease (mean values of the four experiments) of the blood flow to the nonischemic kidney $(\mathrm{p}<0.001)$.

4) Role of the pressor response in the increased $R B F$ produced by angiotensin II during renal ischemia (Table III). In three experiments blood pressures were recorded above and below an aortic constriction in order to follow RVR changes induced by angiotensin II in the ischemic kidney. The aortic constriction was placed just above the left kidney so that the catheter distal to the aortic constriction recorded the perfusion pressure of the ischemic left kidney. If the increase in RBF followed passively the increase in perfusion pressure elicited by angiotensin II, only a small change in RVR would be expected. In two experiments RVR was unchanged, and in a third experiment a $19 \%$ increase followed intravenous administration of angiotensin II during renal ischemia (Table III). These findings are consistent with the position that the increased $\mathrm{RBF}$ produced by angiotensin II during renal ischemia is secondary to the pressor effect of angiotensin II. This position is fortified by the results of intra-aortic injection of angiotensin II.

To exclude or minimize extrarenal effects, particularly reflex nervous effects, angiotensin II was administered into the aorta at the level of the renal arteries. Unless a pressor effect was produced, angiotensin II did not increase RBF during renal ischemia. In two of six observations, intra-aortic administration of angiotensin II (0.1 and $0.01 \mu \mathrm{g}$ per $\mathrm{kg}$ ) did not increase blood pressure; the RBF's remained at control values of 130 and $110 \mathrm{ml}$ per minute, respectively. In four observations intra-aortic angiotensin II $(0.1 \mu \mathrm{g}$ per $\mathrm{kg}$ ) increased blood pressure by $27,12,10$, and $5 \%$. RBF's increased concomitantly by $60 \%$ (control RBF, $75 \mathrm{ml}$ per minute), $25 \%$ (100 ml per minute), 35\% (55 ml per minute), and $40 \%$ (100 ml per minute) respectively. Figure 1 illustrates the failure of intra-aortic administration of angiotensin II to change RBF during renal ischemia. This is contrasted to the earlier renal vasoconstrictor effect of angiotensin II in the same kidney in the absence of ischemia (first panel, Figure 1). Intravenous administration of angiotensin II, which elicited a modest pressor response, produced an increased RBF (Figure 1).

5) Nervous determinants of the altered response of the renal vasculature to angiotensin II. Atropine failed to alter the response to angiotensin II. Before intravenous injection of atropine $(0.2 \mathrm{mg}$ to $2 \mathrm{mg}$ per $\mathrm{kg}$ ) angiotensin II (0.1 $\mu \mathrm{g}$ per $\mathrm{kg})$, intravenously, elicited increases in RVR of 56, 85 , and $128 \%$. After atropine, intravenous angiotensin II elicited increases in RVR of 131, 82, and 132 , respectively. The effect of intra-aortic administration of angiotensin II $(0.1 \mu \mathrm{g}$ per $\mathrm{kg})$ similarly was not reduced by atropine: RVR + $21 \%$ before atropine, $+36 \%$ after atropine. In

TABLE IV

Renal vascular effects of angiotensin II before and after acute denervation of the kidney*

\begin{tabular}{|c|c|c|c|c|c|c|c|c|c|}
\hline & \multicolumn{2}{|c|}{ Dog 1} & \multicolumn{2}{|c|}{$\operatorname{Dog} 2$} & \multicolumn{2}{|c|}{$\operatorname{Dog} 3$} & & \multicolumn{2}{|c|}{ Dog 4} \\
\hline & BP & RBF & BP & RBF & $\mathrm{BP}$ & RBF & & BP & $\mathrm{RBF}$ \\
\hline Control & $\begin{array}{c}m m H g \\
145\end{array}$ & $\begin{array}{c}\mathrm{ml} / \mathrm{min} \\
130\end{array}$ & $\begin{array}{c}m m \mathrm{Hg} \\
95\end{array}$ & $\begin{array}{c}m l / m i n \\
185\end{array}$ & $\begin{array}{c}m m \mathrm{Hg} \\
85\end{array}$ & $\begin{array}{l}m l / m i n \\
210\end{array}$ & & $\begin{array}{c}m m \mathrm{Hg} \\
145\end{array}$ & $\begin{array}{l}m l / \min \\
195\end{array}$ \\
\hline $\begin{array}{l}\text { Angiotensin, } \\
\text { iv, } 0.1 \mu g / k g\end{array}$ & 170 & 85 & 115 & 130 & 125 & 180 & $\begin{array}{l}\text { Angiotensin, } \\
\text { iv, } 0.2 \mu \mathrm{g} / \mathrm{kg}\end{array}$ & 175 & 170 \\
\hline \multicolumn{10}{|l|}{ Denervation $\dagger$} \\
\hline Control & 110 & 135 & 105 & 185 & 100 & 160 & & 105 & 145 \\
\hline $\begin{array}{l}\text { Angiotensin, } \\
\text { iv, } 0.1 \mu \mathrm{g} / \mathrm{kg}\end{array}$ & 150 & 160 & 135 & 195 & 140 & 185 & $\begin{array}{l}\text { Angiotensin, } \\
\text { iv, } 0.2 \mu \mathrm{g} / \mathrm{kg}\end{array}$ & 150 & 170 \\
\hline
\end{tabular}
minute.

*Abbreviations: $\mathrm{BP}=$ mean aortic blood pressure in millimeters $\mathrm{Hg}$; $\mathrm{RBF}=$ renal blood flow in milliliters per

\footnotetext{
$\dagger$ Between the upper and lower set of values the kidney was acutely denervated.
} 
order to explore the relationship between the sympathetic nervous system and angiotensin, acute renal denervation was carried out in four experiments (Table IV). Acute renal denervation resulted in abolition of the renal vasoconstriction elicited by intravenous administration of angiotensin II (Figure 5). Therefore, after denervation of the kidney, the response of the RBF to angiotensin II in the nonischemic state resembled the response obtained during renal ischemia.

\section{Discussion}

The essential observation made in these experiments, alteration of the renal vasoconstrictor action of angiotensin II during renal ischemia, suggests a homeostatic role for angiotensin II that would increase the blood flow to an ischemic kidney. The previously described $(9,10)$ marked sensitivity of the renal vascular bed to the vasoconstrictor effect of angiotensin II was inconsistent with the hypothesis $(6,7)$ that angiotensin II increased RBF in an ischemic kidney by raising renal perfusion pressure.

If the initial event in the production of renal hypertension were renal ischemia, the ischemia could be obscured by the homeostatic mechanism invoked by it (Figure 3). Vasoconstriction was demonstrated in the nonischemic kidney simultaneously with an increased RBF in the contralateral ischemic kidney (Figure 4). A redistribution of regional blood flow would favor the ischemic kidney due to the increased renal perfusion pressure coupled to the loss of angiotensininduced vasoconstriction in the ischemic kidney.

The data presented may reconcile the proponents of renal ischemia as the sine qua non of hypertension (4) of renal origin and those who maintain that there is no constant relationship between nephrogenic hypertension and renal ischemia (12). Thus, the observations of an inconstant reduction in $\mathrm{RBF}$ in the hypertension of coarctation of the aorta (14), the hypertension associated with renal arterial disease (15), and experimental renal hypertension (11) do not exclude an initial renal ischemic stimulus. In Figure 3 almost complete restoration of $\mathrm{RBF}$ followed administration of angiotensin II. The difference between the control RBF and the increased blood flow induced by angiotensin II in the pres-

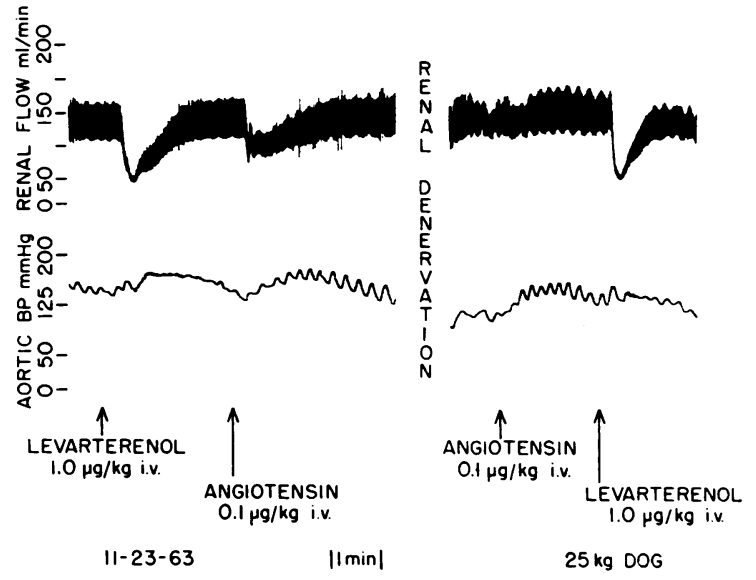

Fig. 5. Renal vascular Response to levarterenol AND ANGIOTENSIN II BEFORE AND AFTER ACUTE DENERVATION OF THE KIDNEY IN A DOG UNDER MORPHINE-CHLORALOSE. Fifteen minutes separated the two panels.

ence of renal ischemia is within the experimental error of the methods commonly employed (paraaminohippuric acid clearance) to estimate RBF. Furthermore, in two experiments during renal ischemia, administration of angiotensin II increased the RBF to above preischemic control values.

Renal ischemia facilitated the rapid development of altered reactivity of the renal bed to angiotensin II. The reduced vascular reactivity progressed at times to abolition of the renal vasoconstrictor effect of angiotensin II in the absence of renal ischemia (Figure 2). Tachyphylaxis to the vascular effects of small to moderate amounts of angiotensin II administered by prolonged intravenous infusion (16) or repeated injections (17) in unanesthetized dogs has not been demonstrated. However, tachyphylaxis expressed by a change in the pressor response (17) or the glomerular filtration rate and renal plasma flow (18) to angiotensin II in high doses has been reported. In secondary hyperaldosteronism, a tachyphylaxis to angiotensin II, even in small amounts, has been suggested to explain the reduced vascular sensitivity to injected angiotensin II (19). During renal ischemia the elaboration of angiotensin II in the ischemic kidney may induce a local vascular tachyphylaxis. The development of reduced renal vascular reactivity to angiotensin II may uncover other sites of activity of angiotensin II, namely, a direct tubular effect of angiotensin II on sodium absorption (20). 
The present experimental design did not permit the complete definition of the factors responsible for the loss of the renal vascular response to angiotensin II during renal ischemia. Several possible explanations, however, may be considered likely, since some of the elements in this experimental preparation that affect the renal vascular response have been separated. The first to be considered is the role of an increased perfusion pressure associated with a local (ischemic kidney's) loss of the renal vascular effect of angiotensin II. This explanation is supported by the essentially unchanged RVR elicited in the ischemic kidney by angiotensin II in the three experiments in which this measurement was made. This would suggest that the increased RBF elicited by angiotensin II during renal ischemia followed passively the increased perfusion pressure. There are known plasma, red cell, and kidney angiotensinases of high specificity $(21,22)$ that may inactivate angiotensin II in the ischemic kidney. A local renal vascular tachyphylaxis may accomplish the same effect, so that the pressor response to angiotensin II is unaccompanied by vasoconstriction in the ischemic kidney. Intra-aortic administration of angiotensin II at the level of the renal arteries failed to dissociate the increase in $\mathrm{RBF}$ from the pressor response to angiotensin II administration (Figure 1). There was no significant relationship $(p>0.05)$ between the pressor response and the degree of increase in blood flow induced by angiotensin II to the ischemic kidney. This would suggest that factors in addition to an increase in blood pressure determined the increase in blood flow to the ischemic kidney in re-

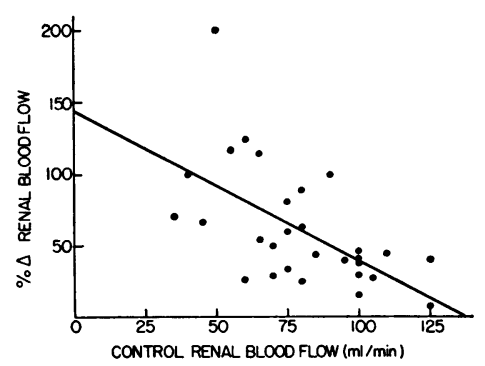

Fig. 6. Per CENT OF INCREASE IN RENAL BLOOD FLOW AFTER ADMINISTRATION OF ANGIOTENSIN II DURING RENAL ISCHEMIA PLOTTED AGAINST THE RENAL BLOOD FLOW OF THE ISCHEMIC KIDNEY BEFORE ADMINISTRATION OF ANGIOTENSIN II. The equation for the regression line is $\% \Delta \mathrm{RBF}=-1.03($ control $\mathrm{RBF})+143.2(\mathrm{p}<0.01)$. sponse to angiotensin II. Thus, there was a significant relationship between the degree of renal ischemia and the percentage increase of RBF elicited by angiotensin II (Figure 6, coefficient of correlation $=-0.59, \mathrm{p}<0.01$ ).

Finally, the relationship of angiotensin II to autonomic nervous activity may determine in part the reversal of the effect of angiotensin II upon the vasculature of the ischemic kidney. In isolated smooth muscle preparations, the activity of angiotensin II is partially dependent upon the release of acetylcholine (23). In the present preparation, however, atropine did not reduce the effect of angiotensin II on the renal vasculature. The vasoconstrictor activity of angiotensin II has been related partially to the integrity of sympathetic nervous activity $(24,25)$. In addition, the vasoconstrictor effect of angiotensin II has been reported to be in part central nervous system dependent $(26,27)$. Acute denervation of the kidney yielded the most unexpected results in the nonischemic kidney, namely, an elimination of the renal vasoconstrictor response to angiotensin II administered intravenously (Figure 5, Table IV). Thus, the vasculature of the denervated kidney in the nonischemic state behaved as that of the ischemic kidney in its response to angiotensin II.

A final explanation of the altered vascular response of the ischemic kidney to angiotensin II must await a more complete elaboration of the mode of action of vasoactive polypeptides, the relation of these substances to the autonomic nervous system, and a fuller definition of the angiotensinase system.

\section{Summary}

In dogs anesthetized with morphine-chloralose the induction of renal ischemia resulted in the loss of the renal vasoconstrictor activity of angiotensin II during the period of ischemia. Before renal ischemia, intravenous administration of angioten$\sin$ II $(0.1 \mu \mathrm{g}$ per $\mathrm{kg})$ elicited a $49 \%$ reduction in renal blood flow (RBF). Constriction of the renal artery reduced the RBF $59 \%$ (from $174 \mathrm{ml}$ per minute to $72 \mathrm{ml}$ per minute). After induction of renal ischemia, intravenous administration of angiotensin II $(0.1 \mu \mathrm{g}$ per $\mathrm{kg})$ produced a $67 \%$ increase in RBF (mean of 42 observations in 24 experiments). An equipressor dose of levar- 
terenol during renal ischemia produced a further reduction in $\mathrm{RBF}(35 \%)$. Renal denervation resulted in the loss of the renal vascular action of angiotensin II in the nonischemic state. A reduction or loss of the renal vascular response to angiotensin II in the nonischemic kidney developed frequently, particularly after prolonged periods of renal ischemia.

\section{Acknowledgments}

We are indebted to Dr. Calvin F. Kay for support, encouragement, and critical review of the work. Dr. Francis C. Wood and Dr. Marilyn E. Hess gave much helpful advice in the preparation of the manuscript. Mr. Robert Bachmann was the illustrator.

\section{References}

1. Frank, M. H. Renin in experimental renal hypertension in monkeys. Circulat. Res. 1963, 12, 241.

2. Helmer, O. M. Presence of renin in plasma of patients with arterial hypertension. Circulation 1962, 25, 169.

3. Page, I. H., and F. M. Bumpus. Angiotensin. Physiol. Rev. 1961, 41, 331.

4. Stamey, T. A. Functional characteristics of renovascular hypertension with emphasis on the relationship of renal blood flow to hypertension. Circulat. Res. 1962, 11, 209.

5. Skinner, S. L., J. W. McCubbin, and I. H. Page. Renal baroceptor control of renin secretion. Science 1963, 141, 814.

6. Skeggs, L. T. Polypeptides of the renal pressor system in Polypeptides Which Affect Smooth Muscle and Blood Vessels, M. Schachter, Ed. New York, Pergamon Press, 1960, p. 110.

7. Morris, R. E., Jr., P. R. Robinson, and G. A. Scheele. The relationship of angiotensin to renal hypertension. Canad. med. Ass. J. 1964, 90, 272.

8. McGiff, J. C., and D. M. Aviado. Differential response of renal and femoral blood flows and vascular resistances. Hypotensive and hypertensive procedures. Circulat. Res. 1961, 9, 1327.

9. Assali, N. S., and A. Westersten. Regional flowpressure relationship in response to angiotensin in the intact dog and sheep. Circulat. Res. 1961, 9, 189.

10. Mandel, M. J., and L. A. Sapirstein. Effect of angiotensin infusion on regional blood flow and regional vascular resistance in the rat. Circulat. Res. 1962, 10, 807.

11. Corcoran, A. C., and I. H. Page. Renal blood flow in experimental renal hypertension. Amer. J. Physiol. 1942, 135, 361.
12. Page, I. H. Discussion in Hypertension-neural and renal mechanisms. Circulat. Res. 1962, 11, 217.

13. Snedecor, G. W. Statistical Methods. Ames, Iowa, The Iowa State College Press, 1956, p. 160.

14. Harris, J. S., W. C. Sealy, and W. DeMaria. Hypertension and renal dynamics in aortic coarctation. Amer. J. Med. 1950, 9, 734.

15. Yendt, E. R., W. K. Kerr, D. R. Wilson, and Z. F. Jaworski. The diagnosis and treatment of renal hypertension with special reference to a case of hypertension due to stenosis of both renal arteries. Amer. J. Med. 1960, 28, 169.

16. Page, I. H., and F. Olmsted. Hemodynamic effects of angiotensin, norepinephrine, and bradykinin continuously measured in unanesthetized dogs. Amer. J. Physiol. 1961, $201,92$.

17. Bock, K. D., and F. Gross. Renin and angiotensin tachyphylaxis. Circulat. Res. 1961, 9, 1044.

18. Bock, K. D., and H.-J. Krecke. Die Wirkung von synthetischem Hypertensin II auf die PAH- und Inulin-Clearance, die renale Hämodynamik und die Diurese beim Menschen. Klin. Wschr. 1958, $36,69$.

19. Johnston, C. I., and A. D. Jose. Reduced vascular response to angiotensin II in secondary hyperaldosteronism. J. clin. Invest. 1963, 42, 1411.

20. Laragh, J. H., P. J. Cannon, C. J. Bentzel, A. M. Sicinski, and J. I. Meltzer. Angiotensin II, norepinephrine, and renal transport of electrolytes and water in normal man and in cirrhosis with ascites. J. clin. Invest. 1963, 42, 1179.

21. Khairallah, P. A., F. M. Bumpus, I. H. Page, and R. R. Smeby. Angiotensinase with a high degree of specificity in plasma and red cells. Science 1963, 140, 672.

22. Glenner, G. G., and P. J. McMillan. A mammalian peptidase specific for the hydrolysis of $\mathrm{N}$-terminal $\alpha$-L-glutamyl and aspartyl residues. Nature (Lond.) 1962, 194, 867.

23. Khairallah, P. A., and I. H. Page. Mechanism of action of angiotensin and bradykinin on smooth muscle in situ. Amer. J. Physiol. 1961, 200, 51.

24. Laverty, R. A nervously-mediated action of angiotensin in anaesthetised rats. J. Pharm. Pharmacol. (Lond.) 1963, 15, 63.

25. Zimmerman, B. G. Effect of acute sympathectomy on responses to angiotensin and norepinephrine. Circulat. Res. 1962, 11, 780.

26. Taquini, A. C., Jr., P. C. Blaquier, and D. F. Bohr. Neurogenic factors and angiotensin in etiology of hypertension. Amer. J. Physiol. 1961, 201, 1173.

27. Bickerton, R. K., and J. P. Buckley. Evidence for a central mechanism in angiotensin induced hypertension. Proc. Soc. exp. Biol. (N. Y.) 1961, 106, 834. 